\title{
A Mixed Study on the Effectiveness of Verbal Praise in Primary School Class
}

\author{
Shiyuan Zhang, ${ }^{1}$ Xinrong Du, ${ }^{2}$ Jie Deng ${ }^{3}$
}

1. Educational Science College, Shangrao Normal University, Shangrao, Jiangxi, China

2. Yuanping Special Education School of Shenzhen, Shenzhen, China

3. Shanghai Normal University, Shanghai, China

Abstract: Verbal praise is frequently used as motivation by teachers in class and truly effective verbal praise plays an important role in maintaining classroom order and stimulating positive student behavior. In this study, students from three classes of $X$ Primary School of Jiangxi Province were interviewed and 328 verbal praise expressions collected. The subsequent empirical study on the effectiveness of verbal praise in four dimensions, namely content, spatiality, subjectivity and time, found that verbal praise generates both shallow and deep effects. The shallow effects act as a foundation for deep effects but do not necessarily result in deep effects. Other conditions are required to actualize a deep effect.

Science Insights Education Frontiers 2021; 10(1):1353-1363.

Doi: 10.15354/sief.21.or060

How to Cite: Zhang, S., Du, X., \& Deng, J. (2021). A mixed study on the effectiveness of verbal praise in primary school class. Science Insights Education Frontiers, 10(1):1353-1363.

Keywords: Verbal Praise, Effectiveness, Mixed Research 


\section{Reflection and Inquiry}

$\mathrm{I}$

NFORMAL, random and motivational, verbal praise is an incentive often used by primary school teachers to encourage students to improve their academic performance through self-discipline. Nevertheless, sustained observation of class teaching reveals that when the same verbal praise expression is repeatedly used in the same classes, or if the same expression happens in different classes, the praised behavior does not necessarily turn into an example followed by other students, nor does it improve class management. This observation triggers reflection and inquiry on the effectiveness of teachers' verbal praise. As a form of appreciation education, does verbal praise work as expected? What is its real effect?

In the past, research on the significance of praise to students has been a major focus in the study of praise. The field of praise hypothesizes that praise motivates students effectively because to the praised students it signifies giving, guidance and appreciation and it meets their emotional need to be noticed, valued and cared for (Zhu, 2008). Being motivated further stimulates students' interest in learning, enlivening the classroom atmosphere, helping teachers to organize topics, and most importantly, has a long-term incentive effect on students. Proper verbal praise can even help develop students' personalities (Wang, 2014). Expectations from others (Yao et al., 2021), intrinsic aspirations (Gao \& Zhang, 2016), self-discipline and learning attitudes (Yang, 2020) resulting from teachers' praise all work together to positively affect students' academic achievement, learning motivation and personality development.

With deepening study on praise, scholars began to consider the effectiveness of praise. Research has suggested that inappropriate praise can have negative effects on students and that excessive praise leads to long-term alienation of praise, and shows undue intentions of surveillance and control on students (Huang, 2013). Moreover, undue praise backfires from the perspective of students' long-term growth, limiting the formation of students' independent personalities and an appropriate attitude toward setbacks, potentially even leading to hypocrisies. Furthermore, some scholars view praise as unnecessary stating that praise is more an evaluation than an affirmation that may

About Authors: Xinrong Du, Yuanping Special Education School of Shenzhen, Shenzhen, China. E-mail: duxr623@nenu.edu.cn

Jie Deng, Post-graduate, Shanghai Normal University, Shanghai, China. E-mail: dengjiexqy@163.com

Correspondence to: Shiyuan Zhang, Vice President and Associate Professor, Educational Science College, Shangrao Normal University, Shangrao, Jiangxi, China.E-mail: tingxiu5120@163.com

Funding: A qualitative study on the teaching life process of primary and secondary school teachers, Jiangxi Social Science Planning Project, Project No.: 15JY11.

Conflict of Interests: None.

(C) 2021 Insights Publisher. All rights reserved.

Creative Commons Non Commercial CC BY-NC: This article is distributed under the terms of the Creative Commons Attribution-NonCommercial 4.0 License (http://www.creativecommons.org/licenses/by$\mathrm{nc} / 4.0 /$ ) which permits non-commercial use, reproduction and distribution of the work without further permission provided the original work is attributed by the Insights Publisher. 
increase children's psychological stress, make them afraid of failure, challenge-avoidant, and consequently weaken their autonomy (Kohn, 1993). As a result, inappropriate praise may damage intrinsic motivation (Weiner, 1992) and risks turning it into extrinsic motivation, thus hindering the functioning of long-term mechanisms of intrinsic motivation. Therefore, some scholars warn against the "trap" of praise and the "sequelae of praise," and suggest a rational application of praise ( $\mathrm{Li}, 2011)$. However, to date, researchers have not defined appropriate praise in terms of its coverage and approach.

To some extent verbal praise is an acceptable means of managing class and motivating students. However, does being right mean it leads to the expected outcome? At present, some disputes exist about the effects, effect path and the effect strength of praise on students. In this study, a mixed research pattern is adopted to examine the effectiveness of praise, including whether the effect of praise varies across settings, personal characteristics of the praised and attribution habits. Previous research suggests that praise shows strong dependent variable attribute, i.e., that the effect of praise depends on the situation and approach in use. To explore the mechanism of verbal praise, questionnaire survey was employed as the main approach, supplemented by group interviews.

\section{Fundamental Framework and Research Structure}

\section{Fundamental Framework}

The goal of education is the growth of individuals pursuant to the social ideal. Verbal praise as a means of education must be targeted at the growth of individuals rather than simply at short-term classroom order. In this sense, the effect of verbal praise covers two layers, a shallow and a deep effect. When the shallow layer is examined, verbal praise is characterized as temporary and unstable. At this level, verbal praise is aimed to motivate the praised student to carry on his good behavior and to set an example for other students to follow. At the deeper layer, praised behaviors are regarded as a part of students' everyday behavior, and the ultimate purpose of praise is to make students accustomed to using the praised behaviors and incorporating such behaviors into their daily life.

Exploration of the effectiveness of verbal praise should cover the following four aspects.

\section{Content Acceptance}

This refers to whether the teachers' praise is well-based and whether praise content is accepted and recognized by students after their subjective perception and interpretation.

\section{Spatial Transfer}

Spatial transfer refers to whether students' individual behaviors transfer to other environments, which indicates whether students recognize and understand the praised be- 
haviors and consciously transmit them to another situation. Can the praised behaviors be presented again and transferred to other situations? For example, can active speaking at Chinese class be transferred to mathematics class or classes of other subjects after being praised?

\section{Subject Transfer}

Experiencing praise oneself and observing others being praised results in different degrees of internalization of the praise and different degrees of habituation for the praised behavior. The subjective dimension of the effectiveness of verbal praise refers to whether the praised behavior will be repeated and transferred interpersonally; that is, whether a praised individual will maintain the praised behavior and whether an individual will imitate and maintain praised behavior observed in others.

\section{Time Continuity}

Time continuity refers to the length of time that students maintain their praised behavior in different situations. The greater the effectiveness of the praise, the longer the praised behavior can persist, which in turn indicates students can consciously maintain praised behavior. Time continuity is about how long the praised behavior will last and what type of praised behavior motivates students to continue behavior to allow habituation.

\section{Research Design}

\section{Research Tools}

The Questionnaire on Effectiveness of Primary School Teachers' Praise and the Interview Outline of primary school teachers' praise were used to collect data.

Before preparation of the questionnaire, the card method was used to conduct group interviews with middle and senior students, and the teachers' verbal praise in class was collected (Figure 1). A total of 328 praise expressions were obtained. Verbal praise is defined as praise applied specifically to a certain behavior of a person or a specific group for the purpose of attaining a desired teaching outcome. Therefore, in the analysis, evaluative language that does not target a specific student, such as "good" and "great," is ignored. Also ignored is teachers' neutral evaluative language for specific students, such as "OK" and "um." Selected praise expressions were sorted and classified as the material for the preparation of the questionnaire. The questionnaire is compiled according to time, spatiality, subject and content dimensions, and includes 31 questions, of which 29 are multiple choices and two are open-ended.

The interview was semi-structured. Based on the four dimensions, students were guided to talk about teachers' praise by telling stories and giving examples to collect information on how the students evaluate the content of teachers' praise, under what circumstances the teachers' praise transferred to other settings, how long the praised behavior persisted, etc. 


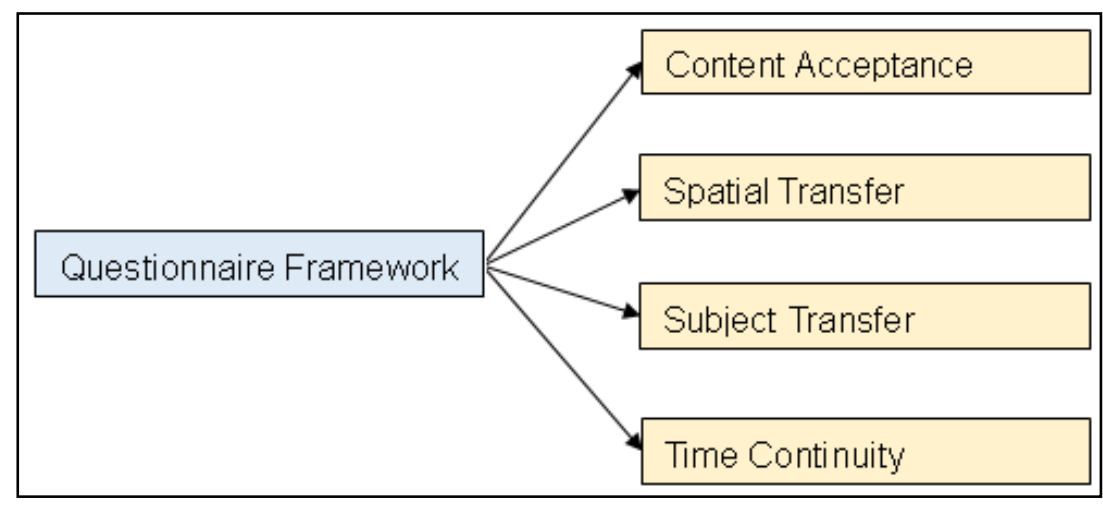

Figure 1. Framework of Questionnaire on Verbal Praise.

\section{Sample Selection}

The survey adopted purposeful sampling and selected X primary school in a county of Jiangxi Province. This primary school was selected as a case study school because it was praised as "a primary school with advanced reform ideas" by the local education authorities, and teachers at the school attached importance to verbal praise in class.

To obtain more accurate data, senior graders were selected as the specific sample. The school has three classes in each of grades 4, 5 and 6, with about 150 pupils in each grade. One class was selected from each grade for the survey and interview.

\section{Survey Data Results and Analysis}

Verbal praise was received by $93.3 \%$ of students, indicating scope was broad. Among surveyed students, $52 \%$ stated they are often praised and $65.3 \%$ of students indicated they expect teachers' praise.

\section{Acceptance of Verbal Praise in Content Dimension}

The list method was used to survey the contents of teachers' verbal praise, including body language and oral language. Normally, teachers would use praise in oral language, complemented with body language. For example, when praising students orally, they would give a thumbs-up sign. The most repeated oral praise expressions were "good", "very good", "you're great", "you did a good job today", etc. Common sentence patterns were "praise X, Y", "Those that did the best are X, Y ...", "You are really + adjective," "You + verb + truly + adverb", "praise + come on!/keep it up /continue to 
work hard", "praise + everyone should learn from him/her", "praise + clapping", "you have made great progress this time, keep up with it", you can ... because..." and so on.

Student response to verbal praise varied. Some students thought: "I was very happy when I was praised at the beginning!" or "When we saw the teacher praise other students, we would make sure that we sit well." However, others said, "These praise words have been repeated for so many times. That's nothing." or "Everyone heard the same praise words. That's nothing special." or "When the teacher said these words, he was perfunctory and didn't add any feelings. The teacher just said it casually."

Further interviews were conducted to examine the reasons for the different responses. All students accepted praise initially, and even acted happily according to the requirements hinted at in the teacher's praise. However, with the passage of time and increased repetitions, some student's enthusiasm faded, and their perception of praise gradually decreased, indicating that these students began to reflect on the praise and could judge the meaning of praise through self-consciousness. It further indicates that to guarantee its effectiveness, praise should not occur with undue frequency. Too much stimulation of superficial praise reduces students' sensibility to it and may induce doubt to the extent that they no longer experience excitement after being praised or expect praise. Therefore, in the dimension of content, verbal praise does play an initial role in behavior reinforcement, for example, with stimulation and efficiency improvement of class management. However, with frequent use of praise, the shallow effect of verbal praise does not increase and the objective of cultivating self-motivation is not achieved.

\section{Field Transfer in Spatial Dimension}

Spatial transfer of verbal praise refers to whether the praised behavior is repeated in other settings without praise. This assesses whether the praised behavior has become a part of students' daily behavior and is maintained for a long time. The survey on the most common situations of praise suggests that spatial transfer of praised behavior is infrequent (see Figure 2).

Survey results of the praised behavior 'preparation before class' show that $45 \%$ of the students persist in preparation before class in a small number of classes, $33.33 \%$ persist only in the class of the teacher issuing the praise, $20 \%$ persist with the behavior in most teachers' classes, and no student persists in preparation before class behavior in all classes, indicating weak internalization and habituation of the praised behavior.

The survey question focusing on 'conscientious fulfillment of assignments' indicates that $30.66 \%$ of students persist in this praised behavior in most teachers' classes, while only $17.33 \%$ of students persisted with this behavior in all teachers' classes.

For the behavior 'being attentive at class, $46.6 \%$ of students persist in this praised behavior in most classes, suggesting that spatial transfer of 'being attentive at class' is stronger than that of 'conscientious fulfillment of assignments' and 'preparation before class.'

Data showed that effective verbal praise has a transfer effect on students' learning behavior, and that degree of transfer differs. However, teacher's verbal praise of 


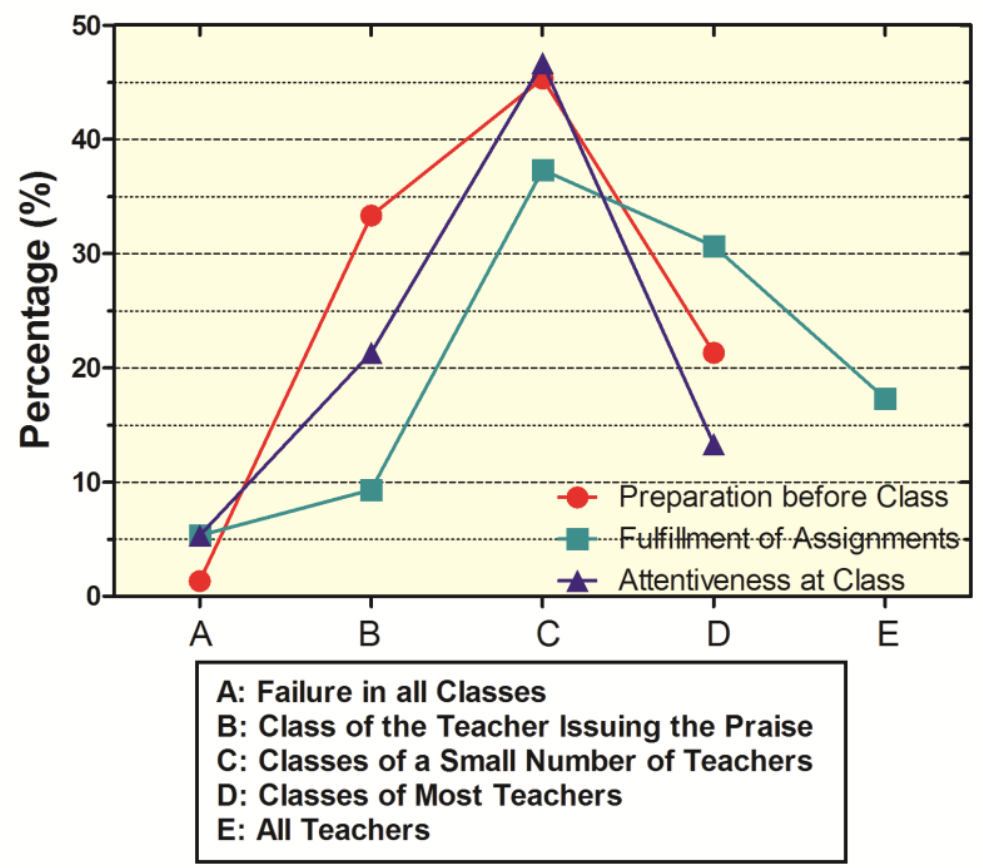

Figure 2. Spatial Mobility of Verbal Praise in Different Situations.

behavior does not create good results in field transfer. When the setting changes, it is difficult to fully extend the student's praised behavior to other environments. That is, when the characters, places or teaching situations in the teaching environment change, the students have difficulty persisting in the praised behavior or internalizing it into their own normalized behavior. Praised behavior migrates and is internalized only in a small number of cases. Spatial field transfer for the three praised behaviors did not surpass $50 \%$.

\section{Verbal Praise Perception and Transfer Effect in the Dimension of Subjects}

Teachers' verbal praise is aimed at an appropriate or excellent behavior of students. Although students are the object of praise, they are the subject of praised behavior. When teachers praise a certain behavior, they are also praising the student generating this behavior. The students place themselves in the position of the subject of the praised behavior and feel proud or inspired. On the same occasion, some students are praised, and some are not. Teachers hope that students who are not praised will learn from the appropriate or excellent behavior of the praised students (Table 1). Praised and non- 
Table 1. Students' Verbal Praise Experience.

\begin{tabular}{lll}
\hline Subject & Option & $\%$ \\
\hline Moods after praise & Extremely Happy & $62.7 \%$ \\
\cline { 2 - 3 } & Moderately Happy & $26.7 \%$ \\
\cline { 2 - 3 } & No Mood Change & $5.3 \%$ \\
\cline { 2 - 3 } & Skeptical of Truthfulness & $5.3 \%$ \\
\cline { 2 - 3 } & Feeling Criticism/Sarcasm & $0 \%$ \\
\hline
\end{tabular}

praised students' experiences differ during the stimulation of teachers' praise. Encouraging the non-praised students to learn from the praised students is one purpose of the teachers' praise. In the survey, we considered responses from both the praised subjects and the non-praised subjects to teachers' verbal praise, the same stimulus.

In non-praised students, $62.27 \%$ learned from the praised students and performed the praised behavior in a small number of classes. In the class where the praise was issued, $21.33 \%$ of the students learned from the praise and followed the praised behavior, while only $13.33 \%$ of the students hoped to follow the praised behavior in most classes.

In praised students, $17.3 \%$ were indifferent when teachers praised others, $22.67 \%$ wanted to learn from the praise but did not act, $26.7 \%$ wanted to learn but persisted for only a few days, and $28 \%$ could always learn from the praise.

In time persistence, most students often or occasionally want to learn from the praise but typically persist for only 1-3 days. If students do act, they do so in only a small number of classes and do not persevere.

The above data indicate that teachers' praise can prolong the praised behavior, but for students not praised, motivation to learn and internalize the good behavior is poor, and sustainability is weak.

\section{Effectiveness in the Dimension of Time}

Effectiveness in the dimension of time is reflected in time persistence of praised behavior. The survey results show that teachers' verbal praise does not affect students' behavioral habits for long. In response to the question, "how long did your most impressive praise last?" most students indicated that when praised by the teacher, they could consciously maintain the praised behavior for about 3-7 days.

For the most impressive cases of praise, $13.33 \%$ affect students for 2-3 days, $25.33 \%$ for $3-5$ days, $26.7 \%$ for one week, and only about $25 \%$ affect them for more than one month. It is not unreasonable to infer that the persistence duration of moderately impressive praise is even shorter. 


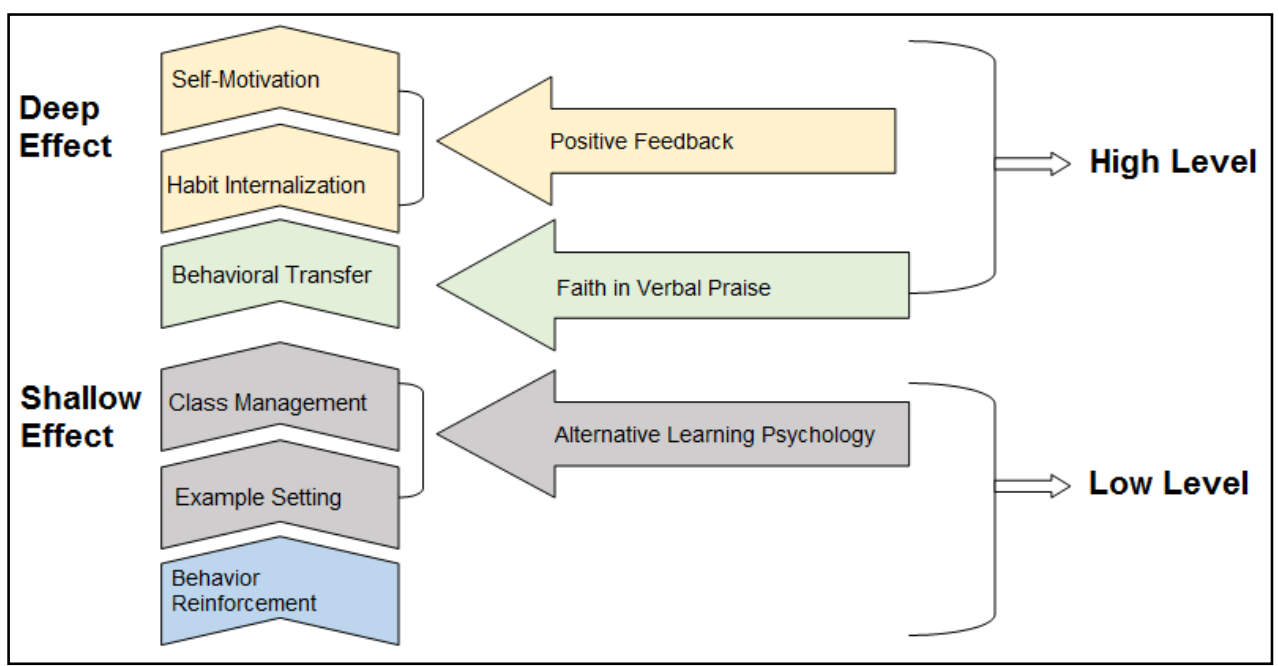

Figure 3. Effectiveness Model of Verbal Praise.

\section{Representation Model of the Effectiveness of Verbal Praise in Primary School Classes}

Verbal praise is more often and more widely used in primary school class than in schools past the primary stage (Figure 3). However, rigorous study of its effects indicates that many conditions are required for verbal praise to work appropriately. According to our results, the effectiveness of verbal praise in primary school class is reflected in shallow and deep effects. Shallow effects include the students' temporary response to praise, involving relatively simple or direct effects on emotion, attitude and motivation. Deep effects reflect a change of the student's internal attainment, emotions and attitudes after reflection and judgment. While verbal praise has a certain effect on behavior reinforcement, example setting and classroom management, it is not easy to obtain its deep effect on behavioral transfer, internal habituation and self-motivation.

The following inferences are drawn from survey results.

$i$. As a means of evaluation in primary school class, verbal praise exhibits its effectiveness at two different levels: shallow level and deep level.

Verbal praise manifests its shallow effect on behavior reinforcement, example stimulation and classroom management. Especially in the beginning, students respond well to praise for reinforcing their behaviors, which is reflected in the fact that praised students will repeat the praised model behavior and observing non-praised students will also replicate the model behavior. This alternative learning psychology mechanism works 
positively in class management. Nevertheless, the ultimate objective of praise is to normalize the praised behavior, facilitate its field transfer, and finally for students to internalize good habits and build self-motivation. However, the survey data shows that only a small percentage of students achieved field transfer and that persistence time for the praised behavior was short, never surpassing a week. Given its shallow effect, verbal praise does not effectively change behavior at a deeper level.

ii. Shallow effects of verbal praise can provide a foundation for deep effects, but creation of a deep effect does not depend solely on satisfying shallow effect requirements.

Evidence from the survey showed that a shallow effect does not necessarily lead to a deep effect. From the perspective of praise content, students respond actively to teachers' praise initially, follow instructions for class discipline and persist in the praised behavior. Yet, over time and with repetition of the praise, the shallow effect is not deepened and instead students grow insensitive to the praise, assuming it is 'casual and superficial.' Eventually, students stop caring about the praise. This result is supported by class observation that verbal praise works well in lower grades for maintaining class discipline but that teachers of high grades cannot maintain class discipline simply using verbal praise, and rather can only achieve discipline by imposing criticisms. Survey data indicate that only $46.67 \%$ of students persisted in 'being attentive at class', while persistence in 'preparation before class' and 'conscientious fulfillment of assignments' was even weaker.

\section{iii. The functioning of deep effects from verbal praise requires necessary psychological} conditions.

Survey data imply that a deep effect is based not only on a shallow effect, but also on certain psychological conditions. Students' faith in verbal praise is the key to the generation of behavioral transfer, habituation and self-motivation. According to the theory of behaviorism, praise is a stimulus that can strengthen people's behavior. On one hand, as a way of strengthening, praise connects students' positive experience with the praised behavior. On the other hand, if students' praised behavior is not further strengthened later, it will gradually subside, with the speed of regression depends on the reinforcement pattern. Skinner (2019) identified two reinforcement patterns: continuous reinforcement and interval reinforcement. A continuous reinforcement pattern strengthens each behavior after the expected behavior appears. If not reinforced continuously in the later stage, the strengthened behavior subsides quickly. In interval, or partial, reinforcement, the expected behavior is strengthened randomly from time to time, and this creates strong resistance to regression. Moreover, the nature of feedback is also key. Praise plays the role of both messenger and inducer. The messenger sends information affirming the praised behavior and the inducer compels the praised person to make further efforts to obtain similar praise. Praise encompasses both affirmation and expectation of students. If the nature of feedback is positive, students are more likely to be motivated. 
To conclude, verbal praise in primary school classes as a mode of behavioral reinforcement does affect students' behavior but these effects are typically shallow, emotional and temporary. When using verbal praise for behavioral reinforcement, teachers should highlight its potential role in students' long-term development. Further research on how praise promotes students' self-efficacy and self-motivation is highly recommended.

\section{References}

Gao, S., \& Zhang, X.K. (2016). Meta-analysis of the Impact of Praise on Children's Intrinsic Motivation . Progress in Psychological Science, 2016(9):1358-1367. DOI: https://doi.org 10.3724/SP.J.1042.2016.0135 $\underline{8}$

Huang, X. L. (2013). Praise and Discipline - On Excessive Praise in Education. Hangzhou Normal University, pp.40-44.

Kohn, A. (1993). Punished by Rewards: The Trouble with Gold Stars, Incentive Plans, A's, Praise and Other Bribes. Boston: Houghton Mifflin, 102.

Li, X.J. (2011). Meditation on Prevalence of Praise. Chinese Journal of Education, 2011(10):80-82.

Skinner, B.F. (2019). The Behavior of Organization: An Experimental Analysis. BF Skinner Foundation.

Wang, C.X. (2014). Research on Application Status Quo and Strategies of Evaluative Verbal Praise in High-grade English Teach- ing in Primary Schools: Taking Jiuquan Primary School in Gansu Province as an Example. Chongqing Normal University, pp.40-43.

Weiner, B. (1992). Human motivation: Metaphors, Theories, and Research. Newbury Park, CA: Sage.

Yang, J. L. (2020). How teachers' praise and questioning affect students' cognitive ability: An analysis using structural equation model based on CEPS data. Education Guide, 2020(5):45-50.

Yao, D.W., Xu, Y.X., Li, H.Y., \& Guo, H.C. (2021). Effects of teachers' praise and criticism on students' academic performance, an intermediary effect analysis based on CEPS data. Peking University Education Review, 2021(1):109-133.

Zhu, G. M. (2008) Implications of Praise and Criticism. Beijing: Beijing University, pp.46-55. 